\title{
Histórias em quadrinhos como ferramenta de releitura e produção textual para alunos do $4^{\circ}$ ano do ensino fundamental
}

Comics as a tool for reading and textual production for students in the 4th year of fundamental education

Marilene da Silva Reis Barreto Joccitiel Dias da Silva

Resumo: A pesquisa ressalta o uso das Histórias em Quadrinhos como ferramenta pedagógica para o desenvolvimento do letramento. Participaram deste estudo alunos do $4^{\circ}$ Ano do Ensino Fundamental I de uma escola pública localizada no sul do Espirito Santo. Seu propósito foi abordar como as histórias em quadrinhos podem contribuir para o desenvolvimento de habilidades de leitura e interpretação de alunos e, para isso, busca-se entender como o uso das histórias em quadrinhos podem favorecer a prática de leitura e interpretação em sala de aula. Os resultados revelaram a potencialidade das Histórias em Quadrinhos (HQs) para despertar o interesse dos alunos, ampliando-Ihes habilidades leitoras, avançando no desenvolvimento da criticidade. A partir dessa pesquisa foi elaborado um guia didático com instruções de como produzir uma releitura de filmes infantis no formato de histórias em quadrinhos.

Palavras-chave: Histórias em quadrinhos; Letramento; Processos de leitura; Atividades lúdicas.

Abstract: The research highlights the use of Comics as a pedagogical tool for the development of literacy. Fourth grade students from a public school located in the south of Espirito Santo participated in this study. Its purpose was to address how comic books can contribute to the development of students' reading and interpretation skills and, for that, we seek to understand how the use of comic books can favor the practice of reading and interpreting in the classroom. The results revealed the potential of Comic Books (Comics) to arouse the interest of students, expanding their reading skills, advancing the development of criticality. From this research, a didactic guide was prepared with instructions on how to produce a re-reading of children's films in the format of comic books.

Keywords: Comics; Literacy; Reading processes; Playful activities.

\section{Introdução}

A aprendizagem de leitura está condicionada a diversos fatores, tais como: a influência familiar, a situação socioeconômica do educando, a classe social, a relação professor e aluno, entre outros, os quais podem tanto facilitar quanto dificultar o processo. Atualmente, as questões referentes às práticas pedagógicas para o ensino de leitura têm recebido atenção de muitos pesquisadores, vez que há a necessidade premente de aprimorar e inovar as 
ações de ensino em favor da prevenção e da redução dos casos de analfabetismo funcional.

Uma das estratégias de ensino bem criativas são as histórias em quadrinhos, considerando-se que são obras em que há a presença dos signos linguísticos e visuais, e se utilizam da linguagem verbal e da linguagem nãoverbal. Os signos possuem a função de auxiliar o homem a interpretar a realidade que o cerca e estão presentes em toda parte.

De acordo com Vergueiro (2010), a introdução das histórias em quadrinhos na educação aconteceu de forma restrita, empregadas, inicialmente nos livros didáticos para ilustrar textos complexos. Com o tempo, notou-se a boa aceitação entre os alunos e as pesquisas mostraram os benefícios de sua utilização nas salas de aula, como apoio pedagógico a diversas disciplinas.

Esta pesquisa pretende entender como as histórias em quadrinhos podem beneficiar o processo de leitura no Ensino Fundamental I. A relevância do tema - Uso das histórias em quadrinhos como fonte de leitura e interpretação de texto para alunos do $4^{\circ}$ Ano - se justifica por se tratar de um gênero que, segundo Ramos (2009, p. 19) [...] "cria uma expectativa de leitura, que não pode ser ignorada" e pelo fato de as histórias em quadrinhos apresentarem diversos elementos que favorecem no desenvolvimento de habilidades críticas no leitor.

O desenvolvimento desta pesquisa também se justifica em razão da importância da utilização das histórias em quadrinhos como fonte de leitura e interpretação dentro da sala de aula, tendo em vista que são textos pequenos, ilustrados, que favorecem a curiosidade em querer ler mais, abrindo caminho para a formação de um leitor crítico. As histórias em quadrinhos também contribuem para o desenvolvimento social, emocional e cognitivo da criança. A sociedade transcorre em uma longa trajetória, na qual as trocas sociais têm acontecido rapidamente, seja através da leitura, da escrita, da linguagem oral ou visual, a escola precisa, pois, reconhecer, e ampliar, a capacidade da leitura e interpretação. A leitura das histórias em quadrinhos configura-se como um instrumento pedagógico eficiente no sentido de despertar o gosto pela leitura (FOGAÇA, 2002, p.125). 
Tendo até aqui apresentado, ainda que em linhas gerais, as potencialidades do uso das histórias em quadrinhos, apresenta-se o problema de pesquisa que norteou sua organização: como as histórias em quadrinhos podem contribuir para o desenvolvimento de habilidades de leitura e interpretação dos alunos do Ensino Fundamental?

Para responder essa questão, delineia-se o objetivo geral da pesquisa, qual seja: compreender como o uso pedagógico das histórias em quadrinhos pode favorecer a prática de leitura e interpretação de alunos do $4^{\circ}$ ano do Ensino Fundamental, promovendo o gosto pela leitura e desenvolvendo a criticidade.

Para alcançar a meta proposta no objetivo geral estabeleceram-se os objetivos específicos: identificar, junto aos alunos, os tipos de histórias em quadrinhos que eles conhecem; apontar as contribuições que a leitura e interpretação das histórias em quadrinhos proporcionam para o desenvolvimento do letramento do educando; descrever de que maneira as histórias em quadrinhos desenvolvem a leitura reflexiva e interpretação crítica dos alunos.

\section{Percurso metodológico}

O percurso metodológico utilizado para atingir os objetivos propostos para essa pesquisa propôs o método da pesquisa-ação, no qual a pesquisadora atuará como articuladora no desenvolvimento da pesquisa, estabelecendo conexão entre os participantes no contexto social.

A pesquisa-ação pode ser configurada dependendo de seus objetivos. Três exemplos poderão facilitar esse entendimento: no primeiro caso o pesquisador tem total controle de sua pesquisa e transmite os comandos; no segundo caso, o pesquisador realiza sua pesquisa em um campo delimitado (escola, empresas etc), ou seja, em um espaço onde existe um líder e outros membros, sendo assim, as relações podem gerar atritos, porque podem haver discordância entre os membros; no terceiro caso, a pesquisa poderá ser realizada em um campo aberto (cidade, comunidade, área rural etc) nesse caso, o pesquisador terá maior autonomia e diversos interesses implicados por 
ser um campo maior. A pesquisa poderá sofrer adequações, conforme o interesse dos membros, e o pesquisador poderá fazer ajustes ao longo do percurso (THIOLLENT, 2011).

A pesquisa terá uma abordagem qualitativa, com interpretações dos fenômenos que envolvem as interações entre alunos e as histórias em quadrinhos em sala de aula, pois objetiva averiguar como os discentes do $4^{\circ}$ ano interagem com a leitura de histórias em quadrinhos, verificando sua contribuição para seu desenvolvimento social, emocional e cognitivo, possibilitando-Ihes uma visão criativa do mundo.

A instituição escolar em que aconteceu a pesquisa está localizada na região sul do Estado do Espírito Santo, Brasil. Trata-se de uma escola municipal do campo, que atende a um público desde a Educação Infantil, Ensino Fundamental I e II e Educação de Jovens e Adultos, funcionando nos turnos matutino, vespertino e noturno.

Essa escola atende aproximadamente 800 alunos, no ano de 2019 e busca o pleno desenvolvimento do discente, preparando-o para interagir socialmente em variados contextos, razão pela qual o discente é elemento principal em seu processo de ensino e aprendizagem. Em todos os níveis e modalidades de ensino, essa instituição busca desenvolver propostas diferenciadas e diversificadas, com a finalidade de atender a todos.

O público-alvo desta pesquisa é formado por 20 crianças e adolescentes da turma do $4^{\circ}$ ano do Ensino Fundamental, com idade entre 10 a 12 anos, todos matriculados nesta instituição de ensino da rede pública de um município localizado no sul do estado do Espírito Santo, uma escola do campo.

Desenvolveu-se uma sequência de atividades, durante as quais 0 discente utilizou sua habilidade de interpretar, fazer inferências, prever, classificar, decidir entre outras ações cognitivas necessárias para executar o ato da leitura.

As etapas da pesquisa foram desenvolvidas no primeiro semestre de 2020, no turno vespertino no horário de 12h10min e 16h40min. Em um período de 07 dias, conforme a organização metodológica e didática. 


\section{Análise dos dados e apresentação dos resultados}

Esta pesquisa apresenta três momentos fundamentais em seu desenvolvimento, que são: atividade de leitura e entrevista estruturada, produções de revista e tirinhas em quadrinhos e o resultado obtido através dessas experiências com os alunos do $4^{\circ}$ ano do Ensino Fundamental I.

A apresentação da pesquisadora ocorreu de forma descontraída, quando o professor regente realizou a aproximação da pesquisadora com a turma, deixando os alunos e a pesquisadora em uma situação confortável para a realização das atividades propostas. Por meio de conversa informal com a turma, investigando o nível de conhecimento dos alunos acerca de histórias em quadrinhos, foi apresentada aos alunos uma caixa contendo inúmeros textos de histórias em quadrinhos e várias revistas, foi proposto, desta forma, um momento de leitura. Essa atividade buscou identificar, junto aos alunos, os tipos de histórias em quadrinhos que eles conhecem e por quais se interessavam e propôs que cada aluno escolhesse uma revista para ler. Em seguida, promoveu-se uma roda de conversa na qual cada aluno pode relatar suas percepções sobre a revista lida e apresentar um breve resumo oral da história.

Dessa forma, favorecer a leitura de quadrinhos em sala de aula contribui para formar um leitor com um nível de letramento que possibilita uma visão que vai além das imagens e das palavras. A realização da primeira atividade proposta permitiu que os alunos mostrassem sua curiosidade, alguns tiveram a oportunidade de ler uma revista em quadrinhos pela primeira vez. O contato com a caixa de leitura foi um momento de prazer e descobertas, quando eles puderam escolher os textos para a leitura e ao mesmo tempo explorar os diversos contextos das narrações. Com isso, vivenciaram um contato diferenciado com o mundo dos quadrinhos.

De acordo com Lemke (2010, p. 5):

"Um letramento é sempre um letramento em algum gênero e deve ser definido com respeito aos sistemas de signos empregados, às tecnologias materiais envolvidas $\mathrm{e}$ aos contextos sociais de produção, circulação e uso de um gênero particular"(...). 
Com isso, é possível que os alunos aprimorem seu nível de letramento a partir de histórias em quadrinhos, fazendo da aula um momento diferenciado com diversas leituras em quadrinhos ampliando o gosto pela leitura. Este momento permitiu inúmeras reflexões, bem como a intertextualidade entre textos e contextos.

Inicialmente, a turma foi questionada se gostava de ler e $100 \%$ do total de 20 alunos afirmaram o seu gosto pela leitura e que leem algum material gráfico, no mínimo, uma vez por semana em suas residências. Evidencia-se, portanto, que a maioria das crianças demostram uma predileção pelas histórias infantis, tendo em vista que, segundo levantamento elaborado a partir de conversas informais com a professora regente, este era o material mais ofertado às crianças nos momentos de leitura em sala de aula, bem como a contação de histórias.

Neste sentido, Penteado (2007, p. 7) afirma que:

A criança, ao apreender a visualidade das histórias em quadrinhos, não está apenas realizando uma soma de imagens. Nos quadrinhos existe uma sucessão em que o sentido de uma imagem só se estabelece por meio de quem a precede. A ação contínua estabelece a ligação entre as diferentes figuras, e essa disposição temporal e espacial das imagens é que organiza seu significado.

A citação dialoga com a percepção dos alunos que afirmaram preferir as histórias em quadrinhos como fonte de leitura. Entendendo que os alunos já possuem o gosto pela leitura, questionou-se a turma de 20 alunos quais os gêneros mais acessados por eles na biblioteca. Para $45 \%$ dos entrevistados o gênero preferido é aventura, 30\% prefere histórias infantis, $20 \%$ aprecia contos e $5 \%$ respondeu poesia.

Nesse sentido, os dados evidenciaram o gosto por aventuras, histórias infantis e contos, narrativas inerentes às histórias em quadrinhos, propiciando a inserção deste tipo de literatura no cotidiano escolar dos alunos, por perceberem as facilidades de interpretação e assimilação a que este tipo de literatura favorece, principalmente ao considerarmos o que defende Penteado (2007, p. 8), para quem 
O trabalho de leitura, na escola, tem por objetivo levar o aluno à análise e à compreensão das ideias dos autores e a buscar no texto os elementos básicos e os efeitos de sentido. É muito importante que o leitor se envolva, se emocione e adquira uma visão de vários materiais portadores de mensagens presentes na comunidade em que vive, buscando sempre a cidadania plena.

As histórias em quadrinhos possuem características peculiares que promovem o encantamento e consequentemente, facilitam o aprendizado, sobretudo no que se refere à leitura e à interpretação, bem como potencializam a produção de textos.

O hábito da leitura é amplamente divulgado no ambiente escolar, no entanto, é preciso uma melhor investigação sobre a postura dos alunos frente à leitura no ambiente familiar. Neste sentido, a pesquisadora se preocupou em buscar informações sobre o hábito de leitura de livros em suas residências. Para $50 \%$ dos entrevistados a resposta foi estudar, $25 \%$ responderam que os livros em sua residência são para fazer trabalhos escolares, $15 \%$ indicou a opção lazer e 10\% respondeu leitura.

Como percebido, a grande maioria dos alunos utilizam os livros, em sua residência, apenas para realização de tarefas escolares, no entanto $15 \%$ deles, percebem nos livros uma fonte de lazer. A leitura é incentivada não apenas em ambiente escolar como também em suas residências. A formação de leitores deve ser algo amplamente trabalhado não apenas nas escolas como também pela família, pois desta forma estaremos contribuindo para a construção de uma sociedade mais rica culturalmente, com cidadãos capazes de interpretar o mundo a sua volta e transformar as realidades (FREIRE, 2001).

Importante nos atentarmos que a pesquisa foi realizada em uma turma de $4^{\circ}$ ano, ou seja, crianças com faixa etária entre 9 e 12 anos, em plena formação psíquica, emocional e cognitiva, em pleno desenvolvimento das habilidades, segundo o estágio operatório concreto, defendido por Piaget (1999). Neste sentido, Rappaport (1981, p.72) comenta que

A criança terá um conhecimento real, correto e adequado de objetos e situações da realidade externa (esquemas conceituais), e poderá trabalhar com eles de modo lógico. Assim, a tendência lúdica do pensamento, típica da idade anterior, quando o real e o fantástico se misturam nas 
explicações fornecidas pela criança, será substituída por uma atitude crítica.

A citação evidencia a importância da leitura e da interpretação de textos de revistas em quadrinhos para a formação da criança. Ao perceber tal importância no processo de formação dos alunos, a pesquisadora se propôs a investigar, ainda, se os alunos têm ou já tiveram contato com este tipo de literatura, e $80 \%$ respondeu que sim, $20 \%$ dos entrevistados disseram que não.

Embora grande parte dos alunos afirmam ter tido contato com revistas em quadrinhos, 4 alunos alegam que, até então, nunca tiveram contato com esse tipo de literatura. Esse fato nos mostra a importância de trabalhar melhor a temática, tendo em vista a relevância das histórias em quadrinhos na formação do processo cognitivo dos alunos, sobretudo na interpretação de textos e compreensão da realidade a sua volta. Penteado (2007, p. 9), ao abordar a questão da formação do leitor, nos alerta que:

Formar um leitor competente, desta forma, significa que ele se torne capaz de compreender o que lê, de admitir que a um mesmo texto podem ser atribuídos vários sentidos, de perceber inclusive o que não está escrito e, além disso, de estabelecer relações com suas leituras anteriores.

Embora nem todo o material gráfico no formato de quadrinhos seja apropriado para crianças, ou Ihes propiciem uma formação saudável, é importante investigar quais os tipos de histórias em quadrinhos que as crianças conhecem e por quais possuem predileção. Em face desse ponto, foi-lhes perguntado quais os personagens mais conhecidos por eles, pois, ao questionar sobre os personagens, é possível, de forma discreta, presumir os títulos, autores e mensagens passados às crianças. A personagem Mônica foi apontada por $25 \%$ dos entrevistados, Magali foi a resposta de $20 \%$, a mesma margem de alunos que responderam nenhum. Para $15 \%$ dos alunos, 0 personagem preferido é o Chico Bento. Outros 10\% responderam Pato Donald, $5 \%$ respondeu Mikey e outros 5\% responderam Chaveco.

Percebeu-se que a maioria absoluta opta por personagens populares que habitam o seu imaginário. Constatou-se, ainda, que um grupo de 4 alunos afirmam não possuir predileção por nenhum personagem devido ao fato de não 
terem contato com revistas em quadrinhos, razão pela qual desconhecem os personagens.

Outro fator que acredita-se contribuir de forma bastante eficiente para a predileção dos personagens elencados pelos alunos é a popularidade dos mesmos através de mídias como TV e cinema. Neste sentido, deve-se considerar Lopes (2012, p. 47), para quem

Os meios de comunicação têm se tornado uma escola paralela às instituições que tradicionalmente eram encarregadas da educação dos indivíduos, a escola e a família. No âmbito da educação informal, a mídia se mostra como importante instrumento por meio do qual a sociedade vem se relacionando e compreendendo o mundo que a cerca.

Destaca-se, portanto, a influência dos meios de comunicação no desenvolvimento do imaginário das crianças, contribuindo fortemente para delinear o seu caráter e, de certa forma, guiar os seus passos, referente a futuras escolhas.

Nessa lógica, os programas televisivos têm se destacado na predileção das crianças, que optam por lançar mão de personagens de histórias em quadrinhos para transmitir suas mensagens incentivadas pelos pais. Posto isso, buscou-se verificar, junto a turma de 20 alunos, se eles conseguem identificar personagens de histórias em quadrinhos apresentados pelas mídias digitais. Para $60 \%$ dos alunos a resposta foi Turma da Mônica, já para $15 \%$ a resposta foi Menino Maluquinho e Pica Pau. Na margem menor de entrevistados, 5\% indicou Super Man e 5\% apontou Homem Aranha.

Ao considerar Vergueiro (2018, p. 180):

Nos quadrinhos infantis, especialmente, pode-se dizer que essa busca possui um atrativo a mais, pois se trata de identificar exemplares da linguagem gráfica sequencial que, ao mesmo tempo em que encantam os estudantes, também desafiam sua criatividade e curiosidade intelectual. Nesse sentido, existe um grande universo - e, em sua maioria, ainda totalmente virgem - a ser explorado. Quem se habilita?.

Percebe-se o grande interesse dos alunos pelo tema apresentado, o qual pode influenciar diretamente seu processo de aprendizagem. Constatouse também um crescente nível de desinibição e participação de todos os 
alunos, inclusive os alunos mais tímidos e com dificuldades de aprendizado, tendo em vista suas contribuições no transcurso da sequência de atividades.

Construindo uma história em quadrinhos: releitura do filme infantil "spirit cavalgando livre"

A proposta a seguir trata-se de uma releitura em forma de oficina, seguindo um passo a passo de construção de histórias em quadrinhos para que os alunos pudessem vivenciar não somente a leitura, mas também a construção do texto, permitindo a eles terem uma experiência de leitura e releitura, de texto e contexto. Isso, porque segundo Eisner (2001), os quadrinhos proporcionam o aprimoramento do conhecimento.

No decorrer da pesquisa, foi apresentado o filme "Spirit Cavalgando Livre", ao qual os alunos assistiram com enorme entusiasmo. Por ser um filme que é transmitido por um canal de assinatura, apenas alguns conheciam.

Por isso, foi proposta aos alunos uma releitura do filme em forma de histórias em quadrinhos, os quais aceitaram a proposta e se mostraram bem interessados. A pesquisadora explicou o passo a passo de como seria feita essa revista e as tirinhas em quadrinhos. Inicialmente, eles fizeram a escolha das imagens que compõem a revista, logo após escreveram os diálogos e, por fim, montaram tudo nas folhas da revista. Foi uma experiência que proporcionou a realização e a adaptação dos gêneros.

Os alunos deram início à produção da revista, de forma coletiva, definiram as imagens que a comporiam, na sala de informática, com nosso auxílio eles selecionaram várias imagens do filme na internet, os desenhos foram impressos e levados para a sala de aula. Em seguida, eles fizeram a escolha dos mesmos e produziram as falas de cada personagem, para que a história fosse montada.

Segundo Ramos e Vergueiro (2018, p. 150):

Uma proposta que estimula a criatividade dos alunos é entregar-lhes algumas das páginas da história em quadrinhos com os balões de texto em branco para que completem o diálogo como bem entenderem. Isso feito, inicia-se uma discussão a partir de uma apresentação espontânea dos 
alunos, procurando entender quais as razões que motivaram a criação do texto desenvolvido (...).

A proposta da atividade anterior vai ao encontro da percepção do autor supracitado, porque é importante estimular a participação do aluno para que ele se sinta motivado para novas práticas e construções. Seguindo essa lógica, a produção de dados desta pesquisa foi favorecida por uma sequência de atividades e ações em torno do tema HQs. As atividades foram pautadas na releitura do filme "Spirit Cavalgando Livre", o qual se tornou uma revista em quadrinhos e seis tirinhas, que demandaram a participação de todos os discentes na confecção.

A execução das atividades favoreceu a compreensão do uso das histórias em quadrinhos como incentivo à prática de leitura, interpretação e releitura. A escolha da atividade de releitura de um filme, em forma de quadrinhos, se deu em razão de termos experiências prazerosas na infância com o gênero textual HQs.

Neste sentido, percebe-se os efeitos criativos nos alunos que, de certa forma se encantaram pelo trabalho em questão, dado o seu caráter lúdico e criativo. Por meio da realização das atividades de leitura dos quadrinhos e da entrevista aplicada, constatou-se que todos os alunos conhecem diversas tirinhas que são encontradas nos livros didáticos, porém, alguns deles não tinham acesso a nenhuma revista em quadrinhos impressa nem digital. Diante desses dados, percebeu-se que é necessária a utilização, com mais frequência, das revistas em quadrinhos ou até mesmo de obras literárias no formato de HQs em sala de aula, pois o aluno precisa ter contato com esse gênero, que possibilita uma leitura diferenciada sobre assuntos diversos. Segundo Ramos (2018, p. 202) "a tira suscita uma rica oportunidade de discussão sobre o tema. $O$ debate a respeito do assunto também integra 0 processo de formação do sentido, na medida em que acrescenta mais informações aos estudantes". Sendo assim, fica clara a contribuição do universo das HQs para o exercício da leitura.

No entanto, é importante um estudo mais aprofundado que vise a corroborar com as questões levantadas a fim de que se proponha maior utilização deste formato de literatura no processo de ensino. 
Importante, ainda, ressaltar que embora as histórias em quadrinhos se mostrem bastante eficientes para desenvolver habilidades leitoras dos alunos, em sala de aula, não devem ser utilizadas como única ferramenta de leitura. É importante que os alunos tenham contato com outros gêneros literários a fim de que seja enriquecido seu universo de leitura, formando leitores capazes de interpretar não apenas os elementos gráficos em um livro, como também o contexto social em que se situa, ampliando sua criticidade.

\section{Considerações finais}

Durante o processo de desenvolvimento deste estudo, foi possível destacar as contribuições da HQ como ferramenta pedagógica para o ensino da língua materna, bem como para a construção estratégias possíveis para a formação plena dos alunos. Trabalhar a leitura é garantir o aprimoramento do grau de letramento individual de cada leitor e esta pesquisa vai ao encontro dessa necessidade, pois a leitura é essencial, e fundamental, para a formação de cidadãos atuantes em uma sociedade que busca garantir o saber pautado no letramento.

Trabalhar por meio de oficinas de releitura de histórias em quadrinhos gera experiências que favorecem a condução das aulas de leitura por meio de ações coletivas. No entanto, é preciso o educador estar atento a sinais que mostrem descontentamento ou até mesmo reprovação dos processos metodológicos empregados, pois há um risco eminente de gerar o efeito contrário, quando as aulas de leitura não são bem planejadas ou não atendem às expectativas dos alunos.

Após o trabalho que buscou verificar a efetividade das histórias em quadrinhos, percebeu-se que se trata de uma ferramenta significativa para a promoção da leitura e do letramento no ambiente escolar. É uma forma muito especial, no momento em que se pretende estimular nos alunos o gosto pela leitura.

Ao considerarmos as histórias em quadrinhos como ferramenta pedagógica, dado o seu poder de encantamento e acesso ao universo infantil, pode-se concluir que o processo de aprendizagem da leitura se torna 
prazeroso e consequentemente mais efetivo, tendo em vista que antes de interpretar os elementos gráficos que formam os textos, os alunos interpretam as paisagens, personagens e todo o contexto exposto nas histórias. Todo esse processo gira em torno de um nível de letramento que é construído gradativamente, a partir das leituras e da vivência de mundo.

Neste sentido, a contribuição das histórias em quadrinhos para o desenvolvimento das habilidades de leitura e interpretação de textos vai além, pois permite a criação de universos de possibilidades interpretativas, no momento em que a criança lança mão do que vê e lê para a projeção de continuidades das histórias no seu campo imaginário. Dessa forma, rompe com a leitura tradicional de decodificação e atinge um nível ascendente de letramento.

Por meio da leitura e interpretação de histórias em quadrinhos, é possível à criança uma reflexão do universo a sua volta e a compreensão de contextos sociais de forma crítica, ao questionar a postura de algum personagem frente a situações semelhantes às vividas no seu cotidiano sobre temas como discriminação, violência, preconceito entre outros.

Este estudo se propôs a trabalhar com uma pequena parcela de alunos, mas é necessário buscar outras formas de avançar nesse campo de questões. Compreendendo a importância das histórias em quadrinhos no processo de formação de leitores, algumas questões foram levantadas sobre os ganhos auferidos a partir de trabalhos desenvolvidos, na parceria entre aluno e professor, referente a esta temática, bem como suas contribuições para o desenvolvimento linguístico de alunos do Ensino Fundamental.

Este artigo demonstrou que a produção de histórias em quadrinhos e as práticas pedagógicas empregadas pela pesquisadora podem servir como uma referência para outros educadores. O guia didático para professores é uma ferramenta que favorecerá novas práticas em sala de aula, considerando que elas podem simplesmente ser executadas, periodicamente, pretendendo ensejar aos educandos a independência leitora, que eles sejam capazes de alcançar a habilidade escrita com proficiência. 


\section{Referências}

EISNER, Will. Quadrinhos e arte sequencial. São Paulo: Martins Fontes, 2001.

FREIRE, Paulo. Pedagogia da autonomia: saberes necessários à pratica educativa. 20. ed. São Paulo: Editora Paz e Terra S/A, 2001.

FOGAÇA, Adriana Galvão. A contribuição das histórias em quadrinhos na formação de leitores competentes. Rev. PEC, Curitiba, v.3, n.1, pp. 121-131, jul. 2002-jul. 2003.

LEMKE, Jay. Letramento metamidiático: transformando significados e mídias metamedia literacy: transforming meanings and media. Disponível em:

< encurtador.com.br/zCLY2>. Acesso em: 1 maio 2020.

LOPES, Mariana Ferreira. Histórias em quadrinhos e midiaeducação: a experiência de oficinas midiaecucativas sobre $\mathrm{HQ}$ com alunos da $4^{a}$ série de uma escola de Cambé-PR. 2012. 237 f.: il. Dissertação (Mestrado em Comunicação) - Universidade Estadual de Londrina, Paraná, 2012. Disponível em: < encurtador.com.br/EPV69>. Acesso em: 8 maio 2020.

PIAGET, Jean. Seis estudos de psicologia. 24. ed. Rio de Janeiro: Forense Universitária, 1999.

PENTEADO, Maria Aparecida. Desvelando o universo das Histórias em Quadrinhos: uma proposta de ação. Disponível em: <http://www.diaadiaeduca cao.pr.gov.br/portals/pde/arquivos/1167-4.pdf>. Acesso em: 5 maio 2020.

RAMOS, Paulo (Orgs.). Os quadrinhos (oficialmente) na escola: dos PCN ao PNBE. In: VERGUEIRO, Waldomiro; RAMOS, Paulo. Quadrinhos na educação. São Paulo: Contexto, 2009.

RAMOS, Paulo. A leitura dos quadrinhos. São Paulo: Contexto, 2009.

RAMOS, Paulo; VERGUEIRO, Waldomiro. Quadrinhos na educação: da rejeição à prática. 2. ed. São Paulo: Contexto, 2018.

RAPPAPORT, Clara Regina; FIORI, Wagner da Rocha; DAVIS, Cláudia. Psicologia do desenvolvimento. São Paulo: EPU, 1981.

THIOLLENT, Michel. Metodologia da pesquisa-ação. 18. ed. São Paulo: Cortez, 2011.

VERGUEIRO, Waldomiro; RAMOS, Paulo. Quadrinhos na educação. 2. ed. São Paulo: Contexto, 2018.

VERGUEIRO, Waldomiro. A linguagem dos quadrinhos: uma "alfabetização" necessária. In: RAMA, Ângela; VERGUEIRO, Waldomiro. (Orgs.). Como usar as histórias em quadrinhos na sala de aula. 4. ed. São Paulo: Contexto, 2010. 


\section{Sobre os Autores}

\section{Marilene da Silva Reis Barreto}

marilene-pk@hotmail.com

Licenciada em Pedagogia pela Fundação Universidade do Tocantins (2011); Licenciada em Artes Visuais pelo Centro Universitário de Jales (2015). Especialista em Educação Infantil e Series Iniciais (2012); Gestão Escolar Integrada (2013); Educação especial inclusiva com ênfase em deficiências (2014). Mestrado em Ciência Tecnologia e Educação pela Faculdade Vale do Cricaré de São Mateus-ES (2020). Atualmente é professora da Prefeitura Municipal de Presidente Kennedy-ES.

\section{Joccitiel Dias da Silva}

joccitiel@gmail.com

Possui graduação em Bacharelado em Matemática pela Universidade Federal do Espírito Santo (1978), mestrado em Matemática pela Universidade Federal do Rio de Janeiro (1994) e doutorado em Matemática pela Universidade Federal do Rio de Janeiro (2002). Professor aposentado da UFES. Atualmente é professor do Mestrado em Ciências, Tecnologia e Educação do Instituto Vale do Cricaré, atuando principalmente nos seguintes temas: materiais elásticos, torção de barras cilíndricas, Princípio de Saint-Venant, equações diferenciais elípticas e equações parciais. Atua na Formação Continuada de Professores do Ensino Fundamental, coordenador do Pró - Letramento em Matemática e Linguagem da UFES. 